\title{
Laterally displaced pecking in monocularly viewing pigeons: A possible factor in interocular mirror-image reversal
}

\author{
I. L. BEALE AND M. C. CORBALLIS \\ UNIVERSITY OF AUCKLAND, NEW ZEALAND
}

\begin{abstract}
Pigeons viewing monocularly showed marked lateral displacement in pecking for grain. This displacement, which occurs towards the seeing eye, could explain why birds trained monocularly to discriminate mirror-image stimuli sometimes favor the negative stimulus when tested with the untrained eye open. Records of off-key pecking obtained during an experiment on interocular transfer lend some support to this idea.
\end{abstract}

Not all aspects of a discriminative stimulus need contribute equally to control of behavior (e.g., Mackintosh, 1965). In particular, Schuck (1960) found that pattern discrimination learning in monkeys was controlled largely by that part of the discriminative stimulus which the monkeys manipulated during learning, stressing the importance of exact stimulus-response contiguity in discrimination learning. There is some reason to suppose, therefore, that a pigeon's behavior whlle pecking at a discriminative stimulus is largely under the control of that part of the stimulus visible to it while it is pecking. This could be an especially important factor in studies of monocular training and of interocular transfer, since pigeons wearing goggles restricting vision to the frontal field and with vision restricted to one eye tend to peck to one side of a stimulus object. This lateral displacement occurs towards the seeing eye, so that a pigeon viewing a stimulus object through its right goggle, for example, will tend to peck towards the right of the object, much as though it wore right-displacing prisms.

We first noticed this lateral displacement in pecking while watching pigeons with one eye occluded pecking for grain in a small circular container. The displacement was so marked in some birds that they would often miss the container altogether. To obtain quantitative data on displaced pecking for grain, we presented grain to each of the birds used in the previous report (Corballis \& Beale, 1967) in a small circular dish of 2 in. in diameter. The grains were stuck onto Scotchtape, fixed sticky-side-up on the floor of the dish, to prevent them from being shaken around by the birds' pecking. Prior to presentation, the dish contained about 100 grains distributed evenly over the floor of the dish. We allowed each bird to peck at the grain until about half the grain was eaten, then we counted the number of grains remaining to the left and right of the dish with respect to the direction from which the bird pecked. We tested each bird with each eye open in turn. The results are shown in Table 1 . They show clearly that all birds tended to peck towards the side of the seeing eye.

Laterally displaced pecking could account for interocular reversal of mirror-image discrimination (Mello, 1965; 1966a, b). A pigeon viewing monocularly can see only about $12^{\circ}$ past its beak (Catania, 1964), perhaps less if it is wearing a goggle over the viewing eye. This means that if a bird pecks on the side of the key towards the seeing eye only about half of the stimulus displayed on the key might be visible to the bird while it is pecking. If $S+$ is a $135^{\circ}$ line and a bird viewing with its right eye pecks to the right of the key, the bird would see the line as occupying predominantly the upper portion of the key, whereas a $45^{\circ}$ line (S-) would appear predominantly on the lower portion. The pigeon may therefore learn to discriminate on the basis of up-down cues rather than angular orientation per se. During testing with the left eye open, assuming the bird now tends to peck towards the left of the key, the $45^{\circ}$ line would now appear to occupy the upper portion of the key while the $135^{\circ}$ line would appear on the lower portion. One might therefore predict that the bird would peck more to the $45^{\circ}$ line (S-) than to the $135^{\circ}$ line (S+), effectively demonstrating mirror-image reversal. Similar explanations of mirror-image reversal can be advanced for other mirror-image stimulus pairs, on the assumption that the behavior of a bird viewing with the right eye is controlled by that portion of the stimulus on the right half of the key, and that of a bird viewing with the left eye by the portion on the left. This may also partially account for the failure of some workers to demonstrate interocular transfer at all under some conditions (e.g., Levine, 1945; Mello, 1966a).

In an attempt to relate laterally displaced pecking more directly to interocular transfer, we obtained records of displaced pecking during the experiment described in the previous report (Corballis \& Beale, 1967). We fastened two layers of paper separated by

Table 1. Number of grains remaining in each half of food dish following a brief period of pecking by birds viewing monocul arly.

\begin{tabular}{ccccc} 
& \multicolumn{2}{c}{$L$ eye open } & \multicolumn{2}{c}{$R$ eye open } \\
Bird & L side & $R$ side & L side & $R$ side \\
\hline A & 1 & 50 & 51 & 5 \\
B & 8 & 49 & 48 & 18 \\
C & 10 & 46 & 48 & 2 \\
D & 9 & 42 & 29 & 15 \\
\hline
\end{tabular}




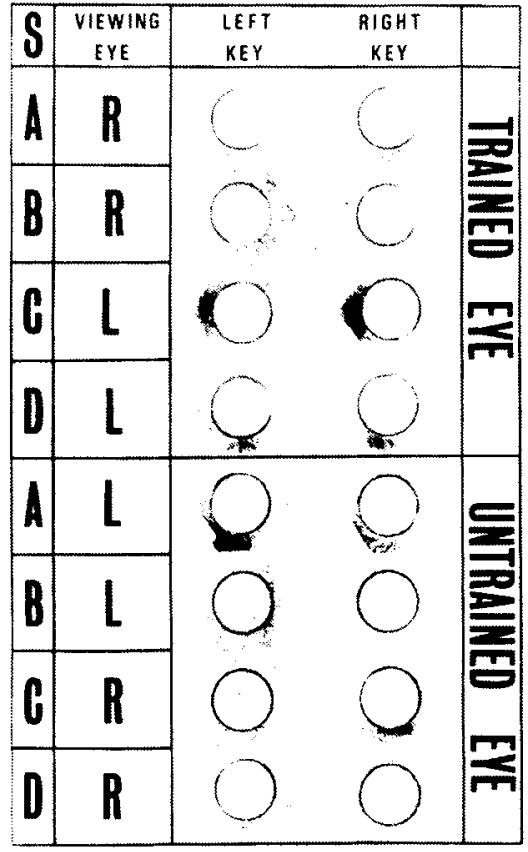

Fig. 1. Carbon records of off-key pecking obtained during sessions with trained and untrained eyes open.

a layer of carbon paper to the surrounds of each key, in order to obtain carbon records of off-key pecks. These records were obtained during the 15th training session of the experiment, and again during an additional testing session on simultaneous discrimination run with the untrained eye open. This additional session was run after the main experiment, and responses to either stimulus were reinforced.

The results are shown in Fig. 1. Since only one of the birds showed any tendency towards mirrorimage reversal, the data are not especially critical to our hypothesis concerming the relation between displaced pecking and mirror-image reversal. Nevertheless Bird $\mathrm{C}$, which was the bird which did slightly favor S- during testing, also showed the most marked displacement of pecking towards the eye which was open during training, although its tendency to peck on the other side when tested with the untrained eye was only slight. Bird B also showed markedly displaced pecking during training, but continued to peck on the same side during testing with the untrained eye. Bird D showed virtually no evidence of displaced pecking, and also showed least preference for $S-$ during test sessions. It appears that learning and adaptation may have occurred in this experiment to lessen the role of displaced pecking, although it is noteworthy that the grain-pecking data shown in Table 1 were obtained after the records of off-key pecking; any learning or adaptation effects evidently did not generalize to the dish of grain.

It is conceivable that adaptation to laterally displaced pecking is more likely during simultaneous than during successive discrimination procedures. In any case it is plausible to suppose that lateral displacement of pecking towards the seeing eye in monocularly viewing birds is a necessary condition for mirror-image reversal. We are currently investigating the role of laterally displaced pecking in interocular transfer following successive discrimination of mirror-image stimuli.

\section{References}

CATANIA, A. C. On the visual acuity of the pigeon. J. exp. Anal. Behav., 1964, 7, 361-366.

CORBALLIS, M. C., \& BEALE, I. L. Interocular transfer following simultaneous discrimination of mirror-image stimuli. Psychon. Sci., 1967, 9, 605-606.

LEVINE, J. Studies in the interrelations of central nervous structures in binocular vision: 1 . The lack of bilateral transfer of visual discrimination habits acquired monocularly by the pigeon. J. genet. Psychol, 1945, 67, 105-129.

MACKINTOSH, N. J. Selective attention in animal discrimination learning. Psychol Bull., 1965, 64, 125-150.

MELLO, N. C. Interhemispheric reversal of mirror-image oblique lines after monocular training in pigeons. Science, 1965, 148, 252-254.

MELLO, N. C. Concerning the interhemispheric transfer of mirrorimage reversal following monocular training in pigeons. Physiol. and Behav., 1966a, 1, 293-300.

MELLO, N. C. Interocular generalization: A study of mirror-image reversal following monocular training in pigeons. J. exp. Anal Behav., 1966b, 9, 11-16.

SCHUCK, J. R. Pattern discrimination and visual sampling by the monkey. J. comp. physiol. Psychol., 1960, 53, 251-255. 